\title{
Mathematical Modelling of Biogas Dehumidification by Using of Counter Flow Heat Exchanger
}

\author{
Aigars Laizāns and Revik Vardanjan
}

\begin{abstract}
This research work deals with the numerical modelling of biogas flow, taking into account heat exchange and condensation on cold surfaces. Different kinds of boundary conditions (air and ground temperatures in summer/winter) and various physical properties of constructions (insulation between layers, wall thickness) are included in the model to make it more general and useful for different biogas flow conditions. MATLAB programming language is used for multiphysical model development, numerical calculations and result visualization.

Experimental installation of the heat exchanger and biogas plant's wall operating under controlled gas/water vapor mixture flow was set up to verify the simulation results. Gas flow at heat exchanger inlet/outlet, as well as gas temperatures and humidity were controlled and measured during number of experiments. Good correlation with modelling results for vertical wall section allows using of developed numerical model for an estimation of parameters for the whole biogas dehumidification system.
\end{abstract}

Index Terms -Biogas dehumidification, numerical modelling, condensation, biogas plant experimental model.

\section{INTRODUCTION}

Dehumidification of biogas at the biomass gasification plants is very important to provide the energy efficient burning of bio methane at the cogeneration systems [1]. Several methods are widely used to reduce the water content in biogas, e.g. chiller/heat exchanger based cooling, usage of different adsorbents like PSA or combination of such approaches [2], [3]. The main problem to use these methods is the necessity to spend substantial amounts of energy, thus reducing overall efficiency of system.

Passive methods of biogas dehumidification are rarely used, and no solutions, that not only do not require energy input, but also decrease losses from biofermentation tank, are offered [4]. Research group examined the dehumidification process by application of double layer heat exchanger with returning part of energy to biofermentation tank.

The construction is presented in Fig. 1. The system consist of supply tube 1 , insulated by layers A and $\mathrm{B}$, is connected to the first layer of the heat exchanger, part 2 of which is up to ground level, but part 3 - underground part connected to the biofermenter wall directly. Condensed water is being collected at the layer connector $4 \mathrm{a}$. Outer layer of the heat exchanger also consist of two parts - one, which is

Manuscript received March 10, 2015; revised January 23, 2016.

Aigars Laizāns is with the Institute of Power Energetics, Latvia University of Agriculture, Jelgava, Latvia (e-mail: Aigars.Laizans@gmail.com).

RevikVardanjan is with the Armgate, Ltd., Riga, Latvia (e-mail: revik@armgate.lv). underground (part 5), and another, which is positioned on the air (part 6). Partially dehumidified biogas is collected in outlet pipe 7 .

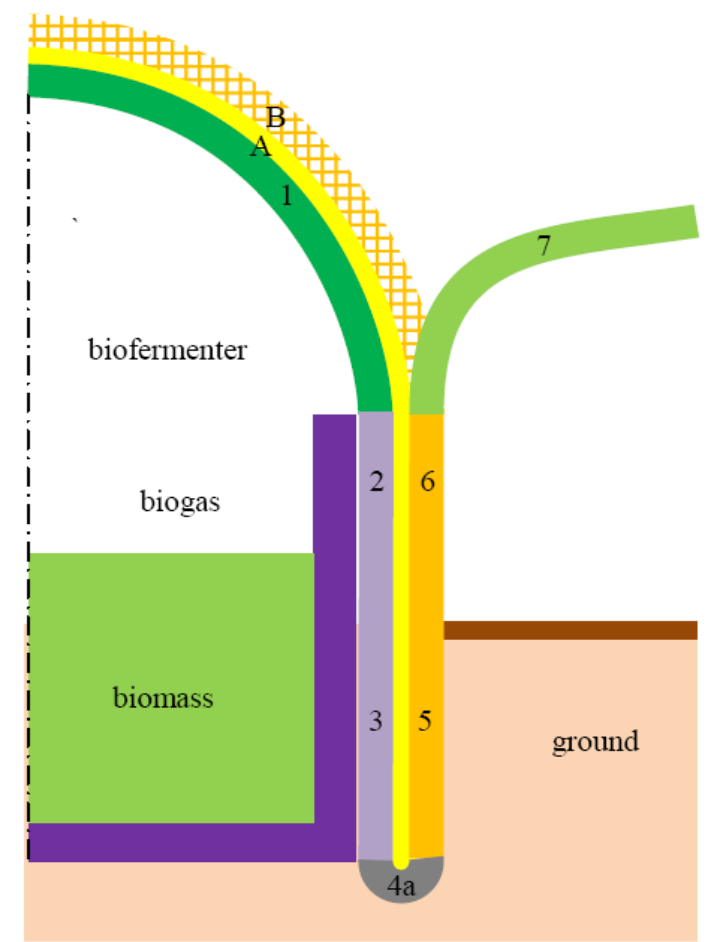

Fig. 1. Double layer heat exchanger mounted on the biofermenter outer wall.

Biogas with temperature which is optimal for the mesophilic fermentation process (usually $+38^{\circ} \mathrm{C}$, close to optimal [5]) and $100 \%$ relative moisture [4] content is directed towards the heat exchanger which is positioned around the biofermentation tank, thus creating of additional insulation layer. As the biogas temperature in the heat exchanger will decrease to $20^{\circ} \mathrm{C}$ in the summer or even below $0^{\circ} \mathrm{C}$ in the winter, condensation of water vapor should occurs. The water from the bottom of the gas shell (part 4a) can be collected and drained away. In addition, upward shell layer allows to further reducing of heat losses. Thus, double layer counterflow biogas heat exchanger is created around the biogas plant.

The main challenge for the researchers was to develop the mathematic model of heat transfer and water vapor condensation.

\section{MATERIALS AND METHODS}

In order to evaluate heat transfer and biogas dehumidification of biogas the model of biofermenter wall with installed double layer heat exchanger was created (Fig. 2). 
Temperature was measured using thermoresistors PT100, connected to 16 channel data logger operated underLabView software. Temperature measurement points are presented in the Fig. 2 as hexagons, but moisture and gas flow measurement points - as triangles. Heat outflow from biofermenter was simulated using flat electric heater operated by fast speed solid switch controlled by microcontroller with feedback from temperature sensor on the heater surface. Temperature on the inner surface of biofermenter wall was set at $+38^{\circ} \mathrm{C}$.

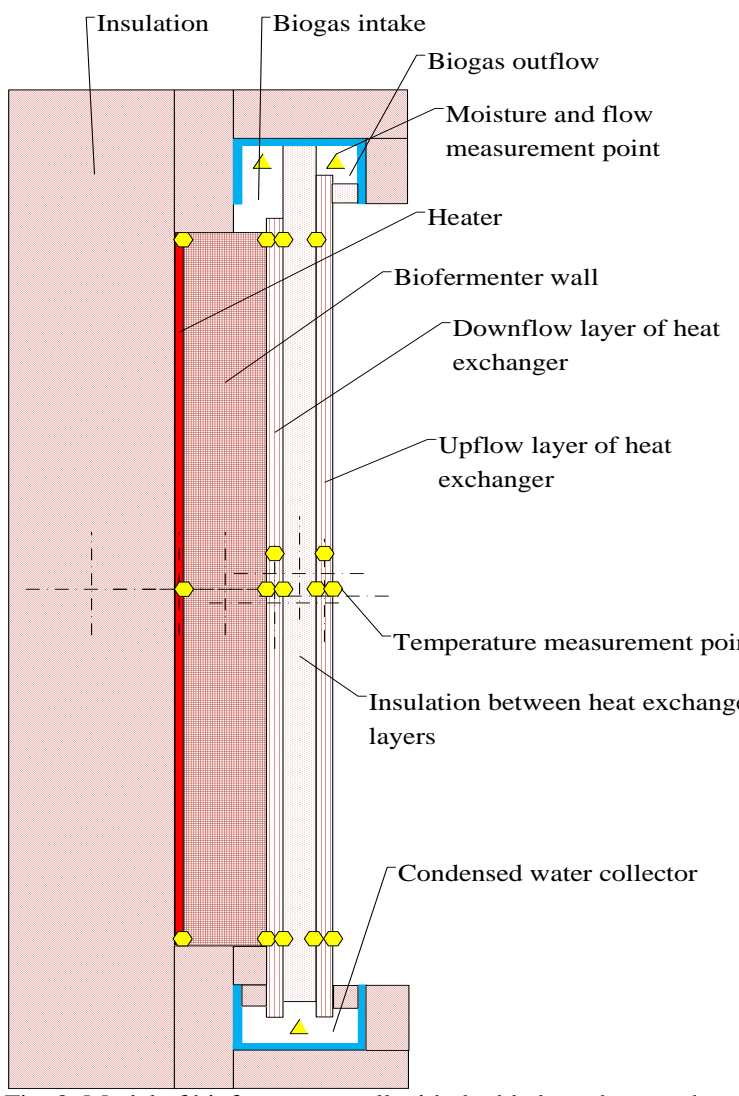

Fig. 2. Model of biofermenter wall with double layer heat exchanger.

Experimental research data were processed and nonlinear regression equations were developed using Ms Excel functions.

Mathematical model of dehumidification and heat transfer process was developed using Matlab Simulink library.

\section{RESULTS AND DISCUSSION}

As biogas enters heat exchanger being saturated by water vapor (100\% relative moisture), and exits also having $100 \%$ relative humidity [4], but at lower temperature, the easiest way to simulate the amount of condensed water is from the equation which describes interdependence between evaporated water mass in the gas and gas temperature. Observations of available literature sources did not reveal direct formula which could show such dependence, so it was decided to create it and to simulate the condensation results under different temperatures.

Water moisture content data for $100 \%$ relative humidity from [3] were used, and the temperature diapason was set to $\left(-10^{\circ} \mathrm{C} ;+50^{\circ} \mathrm{C}\right)-$ the potentially possible range of biogas flow temperatures. The graph showing the interdependence between gas temperature and water mass content in the gas is presented in Fig. 3.

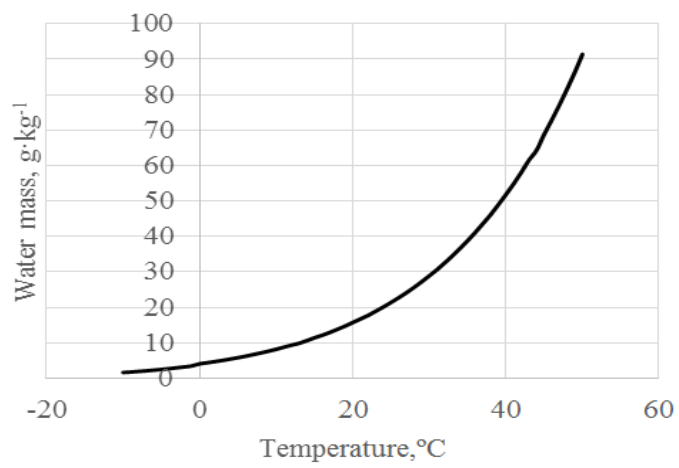

Fig. 3. Interdependence between gas temperature and water mass content in the gas.

Using non-linear regression tools, it was revealed that the best fit between raw data and trend line $\left(R^{2}=1\right)$ was established by using the following fourth level polynomial equation:

$$
\begin{gathered}
m=7.59134 \mathrm{E}-06 T^{4}-2.85632 \mathrm{E}-05 T^{3}+0.010746 T^{2}+ \\
0.329286 T+3.82995
\end{gathered}
$$

where $m$ is water mass content in the gas, $\mathrm{g} \cdot \mathrm{kg}^{-1} ; T$ is temperature, $\mathrm{C}$.

Simulation model for the condensation process by using the (1) formula was created in Matlab Simulink environment (Fig. 4)

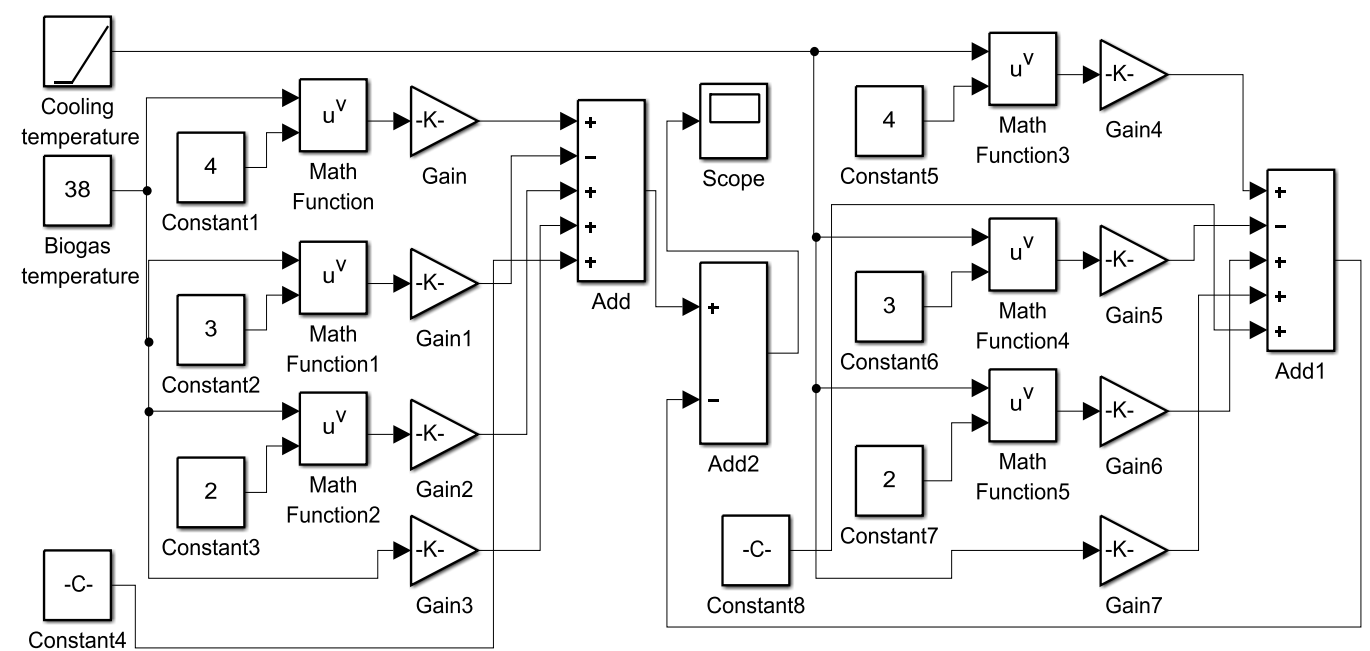

Fig. 4. Simulation model of water vapor condensation. 
Simulation results of theoretical amounts of water condensed from biogas by using passive dehumidification and partial condensation heat return to biofermentation tank are presented in Fig. 5.

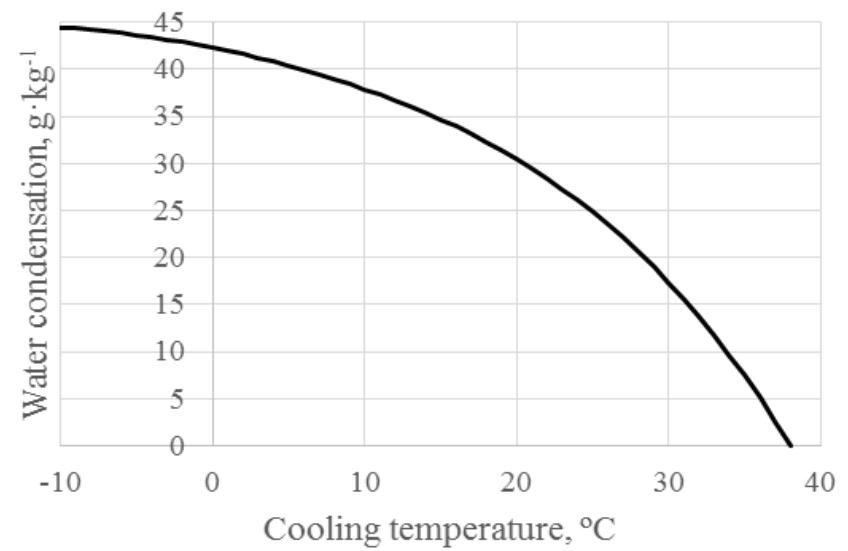

Fig. 5. Condensed water amounts dependence on cooling environment temperature.

Experimental research using the artificial biofermenter wall model with double layer heat exchanger (as seen in Fig. 2) was provided under two different circumstances.

First, the evaluation of comparability of the model to the real conditions was done. The heater control system of the model was stated at $+38^{\circ} \mathrm{C}$, and no gas flow was established through the heat exchanger.

The experiment results are provided in Fig. 6.

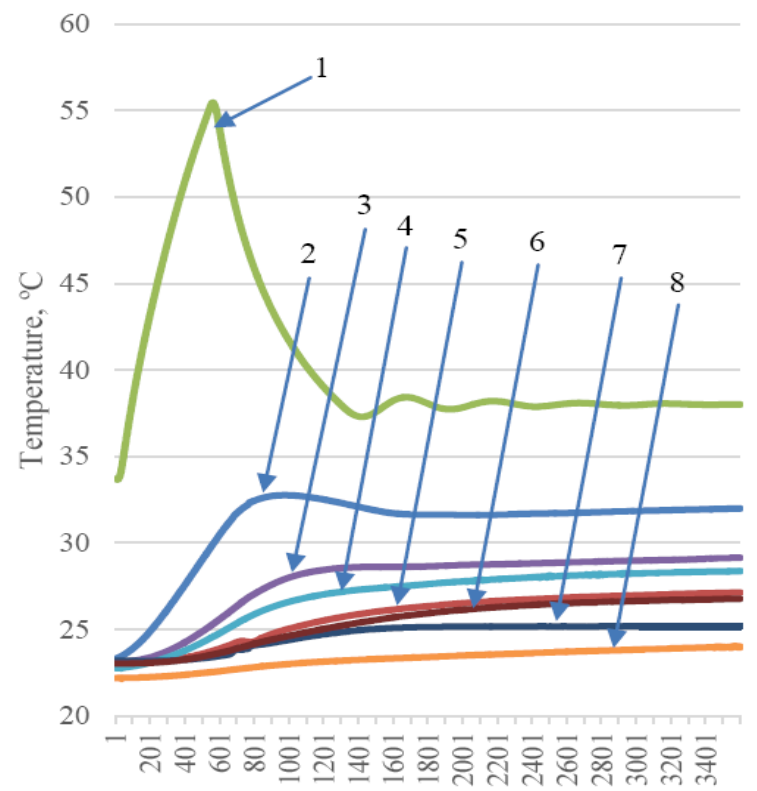

Time, $\mathrm{s}$

Fig. 6. Sample results of field simulation. (1: biofermenter wall - inside, 2 : biofermenter wall — outside, 3: downflow heat exchanger — outside, 4: upflow heat exchanger - inside, 5: biogas intake, 6: biogas output, 7: upflow heat exchanger-outer wall, 8: condenser and joint).

The data received prove that stabilization time for the model is approximately 1 hour, when all transient processes are finalized, and het flux from biogas fermenter through walls and heat exchanger is stable.

Then steady air flow through the heat exchanger was established. Air flow parameters were the following - air flow $-0.01 \mathrm{~m}^{3} \mathrm{~min}^{-1}$, temperature $+32^{\circ} \mathrm{C}$, humidity $100 \%$. Heater temperature was $+38^{\circ} \mathrm{C}$, outside temperature $+24^{\circ} \mathrm{C}$.
The trendlines of the temperatures in all measurement points were very similar to the ones presented in Fig. 6. Stabilization time was similar also.

Data from both experiments are presented in Table I.

\begin{tabular}{|c|c|c|}
\hline Measurement & $\begin{array}{l}\text { Experiment } \\
\text { No.1 (no gas } \\
\text { flow) }\end{array}$ & $\begin{array}{l}\text { Experiment } \\
\text { No.2 (wet gas } \\
\text { flow) }\end{array}$ \\
\hline $\begin{array}{l}\text { Time point, at which } \\
\text { measurements were taken, } \\
\text { seconds }\end{array}$ & 3600 & 3600 \\
\hline $\begin{array}{l}\text { Gas flow, } \mathrm{m}^{3} \min ^{-1} \text {, } \\
\text { Temperatures, }{ }^{o} \mathrm{C} \text { : }\end{array}$ & N/A & 0.01 \\
\hline 1 - biofermenter wall - inside & $38.0 \pm 0.2$ & $37.9 \pm 0.2$ \\
\hline 2 - biofermenter wall - outside & $32.0 \pm 0.2$ & $32.9 \pm 0.2$ \\
\hline $\begin{array}{l}3 \text { - downflow heat exchanger - } \\
\text { outside }\end{array}$ & $2 ., 1 \pm 0.2$ & $30.1 \pm 0.2$ \\
\hline $\begin{array}{l}4-\text { upflow heat exchanger - } \\
\text { inside }\end{array}$ & $28.1 \pm 0.2$ & $27.1 \pm 0.2$ \\
\hline 5 - biogas intake & $28.4 \pm 0.2$ & $33.1 \pm 0.2$ \\
\hline 6 - biogas output & $26.8 \pm 0.2$ & $28.9 \pm 0.2$ \\
\hline $\begin{array}{l}7 \text { - upflow heat exchanger - } \\
\text { outer wall }\end{array}$ & $2 ., 2 \pm 0.2$ & $25.6 \pm 0.2$ \\
\hline $8-$ condenser and joint & $24.0 \pm 0.2$ & $25.9 \pm 0.2$ \\
\hline Relative moisture at exit, $\%$ & N/A & $91.1 \pm 0.1$ \\
\hline
\end{tabular}

As it is seen from the Table I, even with a bit smaller (by $\left.0.1^{\circ}\right)$ temperature on the inside wall and rather high cooling temperature, the temperature on the outside wall is by $0.9^{\circ}$ higher, so the losses through the biofermenter wall decreased, at the same time moisture content was reduced substantially by roughly $25 \mathrm{~g} \cdot \mathrm{m}^{-3}$. Similar trend with temperature increase on all layers was observed, when warm and wet gas was transported through double layer counterflow heat exchanger positioned on the wall of biofermenter.

\section{CONCLUSIONS}

Experimental research proved that the simulation model of dehumidification can be used for condensation water calculations.

Further research is necessary with low temperature cooling agents and conditions in order to understand necessary constructive specifications of proposed double layer counterflow heat exchanger.

\section{ACKNOWLEDGEMENTS}

This research has received financial support of the European Regional Development Fund according to the agreement between LLC "Environment, bioenergetics and Biotechnology Competence Centre" and Investment and Development Agency of Latvia as of April 11, 2011 regarding implementation of the project \# L-Kc-11-0005, project No. 3.6.

\section{REFERENCES}

[1] S. Scott and F. Turra. Six reasons to dry biogas to a low dewpoint before combustion in a CHP engine. [Online]. Available: http://www.parker.com/literature/United\%20Kingdom/PAR6841_Wh itepaper_v3.pdf

[2] World Meteorological Organization, General Meteorological Standards and Recommended Practices, Appendix A, WMO Technical Regulations, WMO-No. 49, 2000. 
[3] Biogas: Cleaning and uses. [Online]. Available: http://www1.agric.gov.ab.ca/\$department/deptdocs.nsf/all/agdex1227 $6 \# \mathrm{CO} 2$

[4] A. Jakovics, S. Gendelis, A. Laizans, and D. Vardanjans, 'Multiphysical mathematical modelling of counterflow heat exchanger with condensation," in Proc. 13th International Conference on Global Research and Education, Riga, Latvia, September 10-12, 2014.

[5] E. O. U. Uzodinma, A. U. Ofoefule, J. I. Eze, and N. D. Onwuka, "Optimum mesophilic temperature of biogas production from blends of agro-based wastes," Trends in Applied Sciences Research, vol. 2, pp. $39-44,2007$.

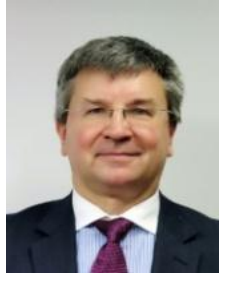

Aigars Laizāns is an associated professor with the Institute of Power Energetics, Latvia University of Agriculture, Jelgava, Latvia.

Dr. Aigars Laizans' research interests are renewable energy solutions, engineering solutions for biomass processing into energy, automation and control systems, transient processes in energy systems, simulation and mathematic modelling in power use and transfer systems.
He has extended experience in international research projects devoted to efficient use of renewable energy resources. As a graduate of engineering fields (degree of mechanical engineer, master degree of power engineering, Ph.D. degree in automatic control of power systems), and business (MBA from Riga Technical University, Riga Business School), he is consulting local business in efficient usage of energy sources.

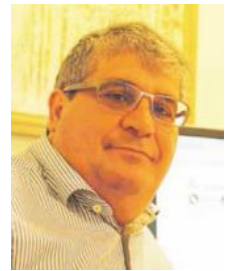

Revik Vardanjan is a researcher at Armgate, Ltd., Riga, Latvia.

Mr. R. Vardanjan is the establisher, owner and CEO of one of the leading research and development companies in Latvia - LLC Armgate. His research interests cover fields of renewable energy, energy efficiency, sustainable solutions in engineering and production. Mr. R. Vardanjan is a graduate from the Health Care Related University, his specific interest is devoted to biological environment engineering solutions. 